2

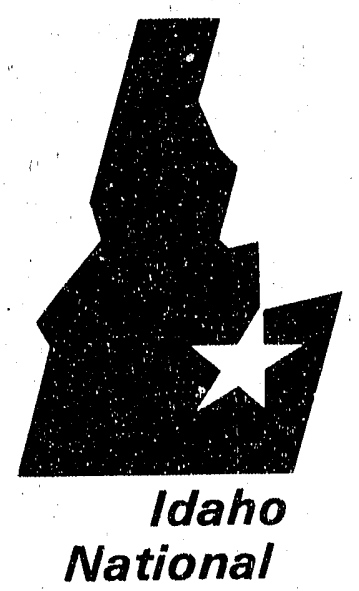

Engineering

Laboratory

\author{
Managed \\ by the U.S. \\ Department \\ of Energy
}

$E G \& G-N E-10083$

$$
\text { Apr\& 1992 }
$$

\section{INTORMAL REPORT}

EMISSIVITY MEASUREMENTS IN SUPPORT OF EXPERIMENTS ON NATURAL CONVECTION BETWEEN A VERTICAL CYLINDER AND A SURROUNDING ARRAY

J. E. O'BRIEN

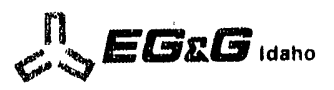

Work performed under DOE Contract No. DE-ACO7-761D01570
} 
This document contains new concepts or the author(s) interpretation of new calculations and/or measurements; accordingly, EG\&G Idaho, Inc. is required by the United States Government to include the following disclaimer:

\section{DISCLAIMER}

This report was prepared as an account of work sponsored by an agency of the United States Government. Neither the United States Government nor any agency thereof, nor any of their employees, makes any warranty, express or implied, or assumes any legal llability or responsibility for the accuracy, completeness, or usefuiness of any information, apparatus, product or process disclosed, or represents that its use would not infringe privately owned rights. References herein to any specific commercial product, process, or service by trade name, tradernark, manulacturer, or otherwise, does not necessarily constitute or imply its endorsement, recommendation, or favoring by the United States Government or any agency thereof. The views and opinions of authors expressed herein do not necessarily state or reflect those of the United States Government or any agency thereor. 
ECG-NE--10083

DE92 012321

\title{
Emissiv ty Measurements in Support of Experiments on Natural Convection between a Vertical Cylinder and a Surrounding Array
}

J. E. O'Brien

December, 1991

\author{
Idaho National Engineering Laboratory \\ EG\&G Idaho, Inc. \\ P. O. Box 1625 \\ Idaho Falls, ID 83415
}

\author{
prepared for the \\ U. S. Department of Energy \\ Idaho Operations Office \\ under DOE Contract no. DE-AC07-76ID01570
}

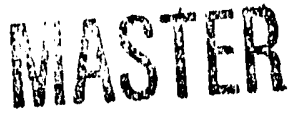




\begin{abstract}
Experimental measurements of surface emissivities of three metallic samples have been obtained in support of an experiment aimed at determining natural convection and total heat transfer for a heated vertical cylinder surrounded by an array of cooled vertical tubes. In some cases, the heated stainless steel cylinder was shrouded by a perforated aluminum outer cylinder. The surrounding cooled tubes were also aluminum. In this experiment, heat transfer from the heated tube and the surrounding outer cylinder will occur by a combination of natural convection and radiation. At temperatures near the meiting point of aluminum, the radiant contribution is particularly important, accounting for $50 \%$ or more of the total heat transfer. Consequently, accurate knowledge of surface emissivities of the heated rods, outer cylinders and surrounding structures is needed in order to predict the system thermal response during the transient. Direct measurements of surface emissivities have been obtained for one stainless steel and two aluminum samples. The ineasurements were obtained using an infrared pyrometer sensitive to the 8-14 $\mu \mathrm{m}$ wavelength range. A procedure for estimating total hemispherical emissivities based on the measured spectral, normal results is also provided.
\end{abstract}




\section{CONTENTS}

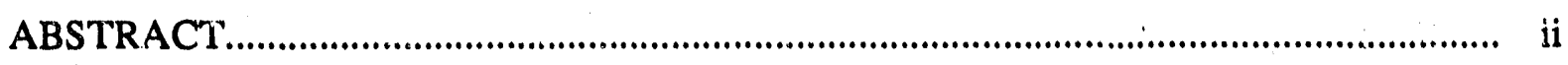

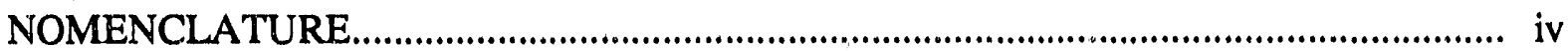

1. INTRODUCTION.......................................................................................

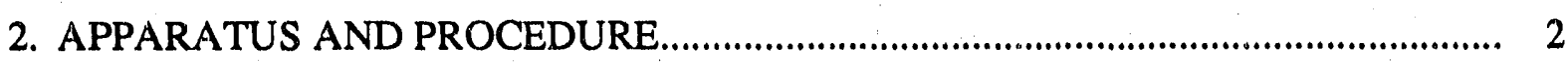

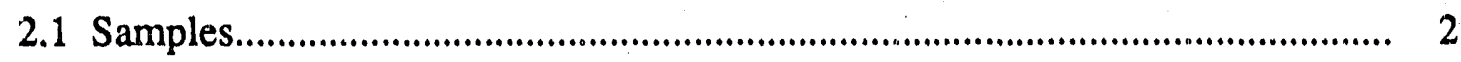

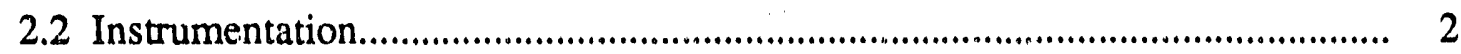

2.3 Data Reduction...................................................................................... 3

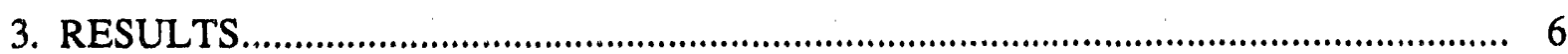

3.1 Normal Spectral Measurements......................................................................... 6

3.2 Relation to Hemispherical Emissivities..................................................... 7

3.3 Estimates of Total, Hemispherical Emissivity .................................................... 8

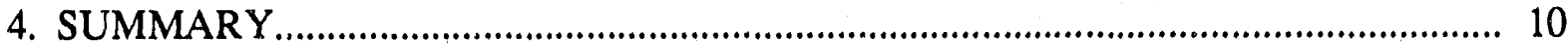

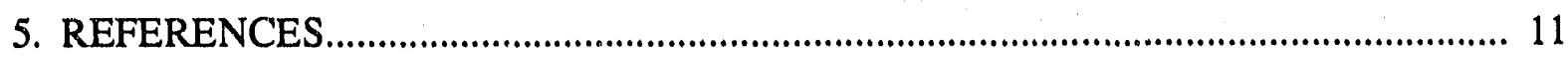

APPENDIX A - Infrared Pyrometer Characteristics and Specifications................................. A1

APPENDIX B - Mathematica algorithms for calculating emissivities and uncertainties..... B1

\section{FIGURES}

1. Schematic of emissivity measurement set-up.

2. Comparison of predicted pyrometer response temperatures to indicated pyrometer temperatures for various emissivity settings................................................................. 13

3. Normal emissivities of stainless steel tube....................................................... 14

4. Normal spectral emissivities of stainless steel (304), from reference [1] .................... 15

5. Normal emissivities of aluminum samples............................................................ 16

6. Normal spectral emissivities for polished aluminum from reference [1].................... 17

7. Relationship between normal and hemispheri emissivities for metals, from [2].... 18

8. Best estimates of total hemispherical emissivities for all samples............................. 19

A.1 Infrared pyrometer characteristics........................................................................... 20

\section{TABLES}

1. Representative emissivity uncertainty values................................................................. 6

2. Ratio of hemispherical to normal emissivity for metallic surfaces............................... 8

3. Estimates of total hemispherical emissivities for each sample...................................... 10 


\section{NOMENCLATURE}

$\begin{array}{ll}A_{1} & \text { surface area of measurement spot, } \mathrm{m}^{2} \\ \mathrm{~A}_{2} & \text { surface area of pyrometer aperture, } \mathrm{m}^{2} \\ \mathrm{E}_{\lambda, \mathrm{b}} & \text { spectral blackbody emissive power, } \mathrm{W} / \mathrm{m}^{2} \mu \mathrm{m} \\ \mathrm{F} & \text { fraction of blackbody radiation in a specified wavelength range } \\ \mathrm{n} & \text { refractive index } \\ \mathrm{q}_{\mathrm{i}} & \text { incident radiant heat flux, } \mathrm{W} / \mathrm{m}^{2} \\ \mathrm{r}_{\mathrm{e}} & \text { electrical resistivity, Ohm } \mathrm{cm} \\ \mathrm{R} & \text { distance between radiant source and pyrometer, } \mathrm{m} \\ \mathrm{T} & \text { temperature, } \mathrm{K} \\ \mathrm{T}_{\mathrm{a}} & \text { mean radiant temperature of surroundings, } \mathrm{K} \\ \mathrm{T}_{\mathrm{S}} & \text { surface temperature, } \mathrm{K} \\ \varepsilon & \text { ernissivity } \\ \varepsilon_{\mathrm{n}} & \text { normal total emissivity } \\ \varepsilon_{\mathrm{n}, \lambda} & \text { normal spectral emissivity } \\ \varepsilon_{\mathrm{h}, \mathrm{h}} & \text { total hemispherical emissivity } \\ \delta \varepsilon & \text { estimated emissivity uncertainty } \\ \kappa & \text { extinction coefficient } \\ \lambda & \text { wavelength, } \mu \mathrm{m} \\ \sigma & \text { Stefan-Boltzmann constant, } 5.67 \times 10^{-8} \mathrm{~W} / \mathrm{m}^{2} \mathrm{~K}^{4}\end{array}$




\section{INTRODUCTION}

A number of nuclear reactors have core geometries consisting of tall, slender arrays of vertical circular tubes. Several types of tubes are present in these arrays including cooling tubes, fuel rods, control rods, and safety rods. During certain hypothesized loss-of-coolant or loss-of-flow scenarios in water reactors, the core may be partially filled with air or another gas. In this case, any thermal energy being dissipated in the tubes is transferred to the surroundings by a combination of natural convection and radiation. Data for natural convection in these complex geometries are sparse or nonexistent. Work described in this report was performed in support of an effort to obtain natural convection and total heat transfer measurements in a geometry corresponding to a single gamma-heated safety rod surrounded by an array of cooling tubes. The safety rod may or may not be surrounded by a perforated aluminum outer cylinder, referred to as a "thimble."

This situation was simulated experimentally using electrical heating of a "safety rod" assembly surrounded by three aluminum cooling tubes in a tall vertical enclosure bounded by a plexiglas shroud. The experiments were carried out in three phases. In the first phase, a stainless steel safety rod was heated alone with no aluminum thimble in place. In the second and third phases, the thimble was in place. The primary objective of the experiment was to provide data which will help to determine the maximum power dissipation level that can be maintained in the safety rod assembly without a catastrophic thermal failure of the thimble. Since the experiment is not exactly prototypical, this power level determination cannot be measured directly. Rather, careful analysis of the experimental data will provide information on overall heat transfer rates and on the relative contributions of convective and radiative heat transfer, allowing for more accurate general prediction of prototypical heat transfer rates for a variety of scenarios.

In order to address the issue of the relative contributions of radiation and natural convection, measurements of surface emissivities of the stainless steel safety rod material, the aluminum thimble material, and the aluminum cooling tubes were undertaken. At temperatures near the melting point of aluminum, the radiant contribution is particularly important, accounting for $50 \%$ or more of the total heat transfer. Although considerable information on emissivities of various materials is available in the literature [e.g., 1-4], there is such a high degree of variability in the data, depending on surface condition and extent of oxidation, for example, that selection of a value from these data bases inevitably involves a level of uncertainty that may be unacceptable for situations in which radiation is important. Direct emissivity measurements of actual components, if feasible, is preferable. 
The scope of the project described herein was to obtain direct measurements of surface emissivities for one stainless steel and two aluminum samples taken from the same materials to be used in the experiments. A description of the measurement and data reduction techniques is given, followed by presentation of results. A procedure for estimating total hemispherical emissivities based on the measured spectral, normal results is also provided.

\section{APPARATUS AND PROCEDURE}

\subsection{Samples}

Three samples were provided for emissivity measurements. The first sample was a 0.94 " OD cylindrical 304 stainless steel safety rod sample identical to the safety rod to be used in the experimental apparatus. The second sample was an aluminum (6063) cylinder identical to the thimble material to be used in the experiments. The third sample was an etched 4" OD aluminum cooling tube. With the exception of the etched cooling tube, each sample was cleaned lightly with isopropyl alcohol before measurements were obtained.

\subsection{Instrumentation}

Emissivities were measured using an infrared pyrometer (Omega model OS-2104 L) designed primarily for measuring temperatures of radiating surfaces. Specifications of this pyrometer are attached to this report as appendix A. The pyrometer features a digital emissivity readout which allows the user to input the estimated emissivity of the radiating surface so that a reasonable estimate of the surface temperature can be made. Conversely, if the surface temperature is known independently, surface emissivity can be measured by adjusting the emissivity input value until the indicated pyrometer temperature matches the known surface temperature. One important specification of the pyrometer used in this study is its wavelength range of sensitivity, which is 8 - $14 \mu \mathrm{m}$. Therefore, the emissivities measured in this study are normal spectral emissivities averaged over the wavelength range of $8-14 \mu \mathrm{m}$. The measurement spot size for the pyrometer is $0.25 \mathrm{in}$. diameter when the pyrometer aperture is located $2 \mathrm{ft}$. from the radiating surface.

A schematic of the emissivity measurement setup used for these tests is shown in Fig. 1. Cylindrical samples were heated internally using commercially available cartridge heaters (Watlow firerod heaters). An on/off temperature controller (Omega model 4001KF) was used to maintain a constant sample temperature during the measurement period at each temperature set point. 
Sample surface temperatures were monitored using four type $\mathrm{K}$ thermocouples spot welded to the sample surface in the pattern shown in Fig. 1. The representative surface temperature at the measurement spot was taken to be the average of the four thermocouple readings. For the safety rod and thimble samples, the gap between the outer diameter of the cartridge heater and the inner diameter of the sample was occupied by a boron nitride insert machined to fit the required dimensions with a minimum clearance gap. Boron nitride was chosen for this application due to its ability to withstand high temperatures, its high thermal conductivity, and its very low thermal expansion coefficient. An aluminum insert machined from aluminum bar stock was used in place of a boron nitride inser for heating the cooling tube sample.

Room air temperature was monitored continuously during the emissivity measurements using a precision RTD thermometer. This temperature was assumed to represent the laboratory mean radiant temperature, $\mathrm{T}_{\mathrm{a}}$. The pyrometer has an internal temperature sensor (at or very close to room air temperature) which the microprocessor treats as the appropriate $T_{a}$ value unless the alternate $\mathrm{T}_{\mathrm{a}}$ mode is activated.

The procedure for obtaining emissivity measurements consisted of heating the sample to the desired temperature, locating the pyrometer aperture exactly $2 \mathrm{ft}$. from the measurement spot in the normal direction, aiming the pyrometer at the measurement spot using the built-in HeNe pointing laser permanently mounted on the pyrometer, and activating the pyrometer. The emissivity setting on the pyrometer was varied until the indicated pyrometer temperature matched the known surface temperature. In measurement situations involving emissivity values lower than 0.1 , the pyrometer emissivity value was set to 0.1 (the lowest available setting) and the indicated temperature was recorded corresponding to an emissivity of 0.1 . The actual emissivity value was obtained for these cases from the post-test data reduction procedure described below.

\subsection{Data Reduction}

The quantity actually measured by the thermopile detector in the pyrometer is that portion of the incident radiant flux (emission plus reflection from the target surface) entering the primaiy aperture of the focusing optics which is imaged on the thermopile and which is in the wavelength band of sensitivity of the pyrometer. Incident radiation is filtered such that the wavelength band of sensitivity is limited. An expression for this incident flux is

$$
\mathrm{q}_{\mathrm{i}, \lambda}=\frac{\mathrm{A}_{1} \mathrm{~A}_{2}}{\pi \mathrm{R}^{2}}\left(\mathrm{E}_{\mathrm{e}, \lambda}+\mathrm{G}_{\mathrm{ref}, \lambda}\right)
$$


where the sum in parentheses represents emission plus reflection from the target surface in the pyrometer wavelength band of sensitivity and the multiplying ratio is the constant geometric extent. Substituting appropriate expressions for emitted and reflected radiant fluxes and noting that the wavelength band set by the filter used in this study was $8-14 \mu \mathrm{m}$,

$$
\mathrm{q}_{(\mathrm{i}, 8-14 \mu \mathrm{m})}=\frac{\mathrm{A}_{1} \mathrm{~A}_{2}}{\pi \mathrm{R}^{2}}\left[\varepsilon \sigma \mathrm{T}_{\mathrm{s}}^{4} \mathrm{~F}\left(\mathrm{~T}_{\mathrm{s}}, 8-14 \mu \mathrm{m}\right)+(1-\varepsilon) \sigma \mathrm{T}_{\mathrm{a}}^{4} \mathrm{~F}\left(\mathrm{~T}_{\mathrm{a}}, 8-14 \mu \mathrm{m}\right)\right]
$$

where the $F(T, \lambda)$ quantities represent the fraction of graybody radiation in the pyrometer wavelength band of sensitivity at temperature $\mathrm{T}$ and $\varepsilon$ is the emissivity of the target surface. A microprocessor is interfaced to the detector. This microprocessor performs the calculation of the temperature of the emitting surface based on the detected radiant flux and two user input quantities: $\varepsilon$ and $T_{a}$. The first quantity, $\varepsilon$, is the emissivity of the emitting/reflecting target surface. The second quantity, $T_{\mathfrak{a}}$, is the mean radiant temperature of the surroundings adjacent to the target surface. The equation solved by the microprocessor in performing the surface temperature calculation is obtained by rearranging eqn. (2) above, yielding

$$
T_{i}=\left[\frac{q_{(i, 8-14 \mu m)}\left(\frac{\pi R^{2}}{A_{1} A_{2}}\right)-(1-\varepsilon) \sigma T_{a}^{4} F\left(T_{a}, 8-14 \mu m\right)}{\varepsilon \sigma F\left(T_{s}, 8-14 \mu \mathrm{m}\right)}\right]^{1 / 4}
$$

Solved in terms of emissivity, eqn. (3) becomes:

$$
\varepsilon=\frac{q_{i, 8-14 \mu m}\left(\frac{\pi R^{2}}{A_{1} A_{2}}\right)-\sigma T_{a}^{4} F\left(T_{a}, 8-14 \mu m\right)}{\sigma T_{s}^{4} F\left(T_{s}, 8-14 \mu m\right)-\sigma T_{a}^{4} F\left(T_{a}, 8-14 \mu m\right)}
$$

In order to verify that the pyrometer microprocessor was indeed using eqn. (3) as the governing equation for temperature measurement, an auxiliary experiment was performed in conjunction with the initial pyrometer qualification experiment. During this experiment, a blackbody surface (Omega BB-1) was maintained at a constant elevated temperature and a series of indicated temperature readings was obtained for different values of emissivity input to the pyrometer. Predictions of indicated temperatures were also estimated from eqn. (3) and compared to the indicated temperatures obtained from the pyrometer. Results of this experiment are shown in Fig. 2. The agreement between the predicted temperatures and the indicated temperatures demonstrates that equation (3) serves as the governing equation for the pyrometer. Temperatures predicted without 
considering the spectral sensitivity of the pyrometer are also shown in the figure as graybody predicted temperatures.

For surfaces with emissivities lower than 0.1 , eqn. (4) was used to calculate the actual surface emissivity from the indicated surface temperature (from the pyrometer) and the actual suriace temperature (from the thermocouples). Knowledge of the pyrometer-indicated temperature, the pyrometer emissivity (eg., 0.1 ), and the mean radiant temperature, $\mathrm{T}_{\mathfrak{a}}$, allows for determination of the radiant flux product:

$$
\mathrm{q}_{\mathrm{i}, 8-14 \mu \mathrm{m}}\left(\frac{\pi \mathrm{R}^{2}}{\mathrm{~A}_{1} \mathrm{~A}_{2}}\right)=\varepsilon \sigma \mathrm{T}_{\mathrm{s}}^{4} \mathrm{~F}\left(\mathrm{~T}_{\mathrm{s}}, 8-14 \mu \mathrm{m}\right)+(1-\varepsilon) \sigma \mathrm{T}_{\mathrm{a}}^{4} \mathrm{~F}\left(\mathrm{~T}_{\mathrm{a}}, 8-14 \mu \mathrm{m}\right)
$$

Eqn. (4) is then applied using this value for the radiant flux product and the actual values for surface temperature and the known mean radiant temperature.

Uncertainties in the emissivity measurements were quantified using the uncertainty analysis procedure outlined in [6]. This procedure requires evaluation of the partial derivatives of the dependent variable ( $\varepsilon$ in this case) with respect to the independent variables $\left(\mathrm{T}_{\mathrm{S}}, \mathrm{T}_{\mathrm{a}}\right.$, and $\left.\mathrm{q}_{\mathfrak{i}}\right)$. In particular,

$$
\delta \varepsilon=\left\{\left(\frac{\partial \varepsilon}{\partial \mathrm{q}} \mathrm{dq}\right)^{2}+\left(\frac{\partial \varepsilon}{\partial \mathrm{T}_{\mathrm{a}}} \mathrm{dT}_{\mathrm{a}}\right)^{2}+\left(\frac{\partial \varepsilon}{\partial \mathrm{T}_{\mathrm{s}}} \mathrm{dT}_{\mathrm{s}}\right)^{2}\right\}^{1 / 2}
$$

The required partial derivatives are obtained in principle directly from eqn. (2). Analytical determination of these derivatives is complicated by the appearance of the F functions in eqn. (4).

This function has the form:

$$
F(T, 8-14 \mu \mathrm{m})=\frac{\int_{8}^{14} E_{\lambda, b} d \lambda}{\sigma T^{4}}
$$

and therefore the partial derivatives of $\varepsilon$ with respect to temperatures must be evaluated numerically. An algorithm (copy attached as appendix B) for estimating uncertainties was developed using Mathematica [7]. Values for the uncertainties in $T_{s}, T_{a}$, and $q_{i}$ were obtained from standard thermocouple accuracy specifications and the pyrometer specifications, respectively. Re- 


\begin{tabular}{|c|c|c|c|c|c|}
\hline \multicolumn{5}{|c|}{ Table 1. Representative emissivity uncertainty estimates. } \\
\hline & $\mathrm{T}_{\mathrm{S}}=300 \mathrm{~K}$ & 400 & 500 & 700 & 900 \\
\hline$\varepsilon=0.1$ & .526 & .0175 & .00729 & .00334 & .00246 \\
\hline .2 & .4731 & .0171 & .00814 & .00494 & .00420 \\
\hline .3 & .4248 & .0178 & .00978 & .00690 & .00611 \\
\hline .4 & .3832 & .01949 & .0119 & .00897 & .00807 \\
\hline .5 & .3509 & .02194 & .01426 & .0111 & .0101 \\
\hline
\end{tabular}

sults of the uncertainty calculations are summarized in Table 1. This table includes typical uncertainty values as a function of $\varepsilon$ and $\mathrm{T}_{\mathrm{s}}$. Overall uncertainties are most sensitive to changes in sample temperature. Uncertainties are highest for temperatures near room temperature and decrease significantly at higher temperatures.

\section{RESULTS}

\subsection{Normal Spectral Measurements}

Emissivity results for the stainless steel safety rod sample are presented in Fig. 3. Prior to heating, this sample had a shiny polished appearance. Measured emissivities for this sample increased slightly with temperature, from a value of 0.11 at $335 \mathrm{~K}$ to a value of 0.135 at $850 \mathrm{~K}$. Visual inspection of the sample indicated a surface darkening which became apparent at temperatures above approximately $600 \mathrm{~K}$. Fig. 4 is a reproduction of spectral normal emissivity data for stainless steel (304) from reference [1]. Measured emissivity values for our safety rod sample are consistent with the values presented in Fig. 4 for the "unoxidized" sample in the $8-14 \mu \mathrm{m}$ range. According to [4], total normal emissivities for typical polished stainless steels range from 0.17 to 0.30 over a temperature range from $300-1000 \mathrm{~K}$. A value of 0.12 appears to be more representative of the total normal emissivity of the present safety rod sample (and for the sample of Fig.4) at $300 \mathrm{~K}$ since the peak emission wavelength at $300 \mathrm{~K}$ is in the middle of our measurement range of sensitivity $(8-14 \mu \mathrm{m})$.

Emissivity results for the aluminum samples are presented in Fig. 5. Measured thimble emissivities dropped from 0.11 to 0.08 over a temperature range from $350 \mathrm{~K}$ to $720 \mathrm{~K}$. Results for the 
cooling tube exhibited a similar but more drastic downward trend with temperature from 0.11 at $340 \mathrm{~K}$ to 0.061 at $480 \mathrm{~K}$. The explanation for the apparent drop in measured emissivities of these samples with increasing temperature is unknown. For the cooling tube, low-temperature emissivity values were remeasured and duplicated on the second and third heatings, indicating consistency in the measurements and data reduction procedure. These near-room-temperature measurements have a high degree of uncertainty, especially for low values of emissivity, due primarily to extreme sensitivity to the mean radiant temperature, $\mathrm{T}_{\mathrm{a}}$, of the surroundings. For a surface temperature of $350 \mathrm{~K}$ and a measured emissivity of 0.1 , uncertainty in $\mathrm{T}_{\mathrm{a}}$ of only $1^{\circ} \mathrm{C}$ results in uncertainty in emissivity of \pm 0.013 , which is $13 \%$ of the measured value.

Spectral normal emissivities of "polished" aluminum samples from reference [1] are presented in Fig. 6. Note that there is aiso a slight drop in the $8-14 \mu \mathrm{m}$ average emissivity for these samples between $599 \mathrm{~K}$ and $697 \mathrm{~K}$. These samples were maintained at their respective temperatures for extended periods of time ( $15 \mathrm{hrs}$.) before measurements were obtained, however [1]. These data indicated emissivities of $0.04-0.06$ in the $8-14 \mu \mathrm{m}$ range for temperatures from 599 $805 \mathrm{~K}$. Measurements for our thimble material indicate an emissivity of 0.08 for this wavelength and temperature range. Therefore, selecting 0.045 as a reasonable value to represent polished aluminum in the $8-14 \mu \mathrm{m}$ range, total normal emissivities for the thimble are expected to be about $78 \%$ higher than total normal emissivities of polished aluminum. Measurements for our cooling tube indicate an emissivity of 0.06 in the $8-14 \mu \mathrm{m}$ range for the highest temperatures measured. Therefore, total normal emissivities for the cooling tube are expected to be about $20 \%$ higher than total normal emissivities of polished aluminum. Total hemispherical emissivities of polished aluminum samples range from approximately 0.04 to 0.06 over the temperature range $300-600 \mathrm{~K}[4]$.

\subsection{Relation to hemispherical emissivities}

Results discussed above refer to normal emissivities. In general, emissivity is independent of direction only for diffuse emitters. Since the emissivity of metals generally increases with angle away from the normal, the ratio of hemispherical to normal emissivity, $\varepsilon / \varepsilon_{\mathrm{n}}$, for metals is generally greater than 1.0. In particular, this ratio varies from about 1.3 for low emissivities to about 0.9 at high emissivities as shown in Fig. 7 (reproduced from [2]). The ratio plotted in Fig. 7 is not exact, since it is based on inexact theory and the assumption that the index of refraction, $n$, is equal to the extinction coefficient, $K$. In addition, these values correspond to the case of a polished surface. Unpolished surfaces would tend to have $\varepsilon / \varepsilon_{n}$ values closer to 1.0 . For the emissivity range of the samples included in this study, approximate values of $\varepsilon / \varepsilon_{\mathrm{n}}$ are tabulated in 


\begin{tabular}{|c|c|}
\hline $\begin{array}{l}\text { Table 2. Ratio of hemispherical to } \\
\text { normal emissivity for metallic surfaces. }\end{array}$ \\
\hline \hline & $\varepsilon / \varepsilon_{\mathrm{n}}$ \\
\hline$\varepsilon=0$ & 1.33 \\
\hline 0.05 & 1.27 \\
\hline 0.10 & 1.225 \\
\hline 0.15 & 1.185 \\
\hline 0.20 & 1.145 \\
\hline 0.25 & 1.105 \\
\hline 0.30 & 1.075 \\
\hline 0.35 & 1.055 \\
\hline
\end{tabular}

Table 2 as a function of hemispherical emissivity [5]. For example, for a hemispherical emissivity of $0.05, \varepsilon / \varepsilon_{\mathrm{n}}$ is 1.27 . For a hemispherical emissivity of 0.3 , however, $\varepsilon / \varepsilon_{\mathrm{n}}$ is only 1.075 .

Another method for estimating the $\varepsilon / \varepsilon_{\mathrm{n}}$ ratio is provided in [2]. This method makes use of the following equations:

$$
\begin{array}{cc}
\varepsilon / \varepsilon_{\mathrm{n}}=\frac{0.751 \sqrt{\mathrm{r}_{\mathrm{e}} \mathrm{T}-0.396 \mathrm{r}_{\mathrm{e}} \mathrm{T}}}{0.576 \sqrt{\mathrm{r}_{\mathrm{e}} \mathrm{T}}-0.124 \mathrm{r}_{\mathrm{e}} \mathrm{T}} \quad\left(0<\mathrm{r}_{\mathrm{e}} \mathrm{T}<0.2\right) \\
\varepsilon / \varepsilon_{\mathrm{n}}=\frac{0.698 \sqrt{\mathrm{r}_{\mathrm{e}} T}-0.266 \mathrm{r}_{\mathrm{c}} \mathrm{T}}{0.576 \sqrt{\mathrm{r}_{\mathrm{e}} \mathrm{T}}-0.124 \mathrm{r}_{\mathrm{e}} \mathrm{T}} \quad\left(0.2<\mathrm{r}_{\mathrm{e}} \mathrm{T}<0.5\right)
\end{array}
$$

where $r_{e}$ is the electrical resistivity of the surface material in ohm-cm. Using values of 72 and 4 $\mu \Omega$-cm for the respective electrical resistivities of stainless steel (304) and aluminum alloy [8] at approximately $300 \mathrm{~K}$, values of $\varepsilon / \varepsilon_{\mathrm{n}}$ equal to 1.24 and 1.29 are obtained. These values would be representative for polished stainless steel and aluminum samples at room temperature. Samples with roughness and/or oxidation will have values of $\varepsilon / \varepsilon_{n}$ closer to 1.0. Also, the ratio of $\varepsilon / \varepsilon_{n}$ is dependent on temperature. Fig. 7 is more useful for estimating $\varepsilon / \varepsilon_{n}$ ratios at various temperatures when $\varepsilon_{\mathrm{n}}$ is known. Information on the temperature dependence of the relevant electrical resistivities would be needed in order to apply eqns. (8) and (9) at various temperatures.

\subsection{Estimates of total, hemispherical emissivities}

Estimates of total, hemispherical emissivities were obtained at $400 \mathrm{~K}$ and $800 \mathrm{~K}$ in the following 
manner. Total normal emissivities were first estimated from the measured $8-14 \mu \mathrm{m}$ values by comparing the measured values to the spectral normal data presented in Figs. 4 and 6. For example, for the safety rod, measurements agreed reasonably well with spectral normal data in the 8 $14 \mu \mathrm{m}$ range presented in Fig. 4 for the unoxidized sample. This spectral distribution was therefore assumed to be representative of the safety rod. To obtain a total normal emissivity at $400 \mathrm{~K}$, the spectral value at $7.2 \mu \mathrm{m}$ from Fig. 4 was assumed to be representative. For the $800 \mathrm{~K}$ total normal emissivity, the spectral value at $3.6 \mu \mathrm{m}$ was assumed to be representative.

This procedure includes two additional assumptions. The first is that the spectral emissivity at the peak wavelength for emission is approximately equal to the total normal emissivity. This assumption is reasonable since the off-peak contributions fall off rapidly with wavelength. For example, at $800 \mathrm{~K}$, the peak wavelength is approximately $3.6 \mu \mathrm{m}$ and the blackbody distribution is down by almost an order of magnitude at $2 \mu \mathrm{m}$ and $10 \mu \mathrm{m}$. The variation in spectral emissivities is small over this range and the average emissivity over this range is very close to the $4 \mu \mathrm{m}$ value. The second assumption is that over the temperature range of $400-800 \mathrm{~K}$, the spectral distributions of emissivity do not change significantly. This assumption will be reasonable as long as the surface condition is not significantly altered due to heating (eg. oxide layer formation). Furthermore, the measurements obtained in this series indicated very small changes in band spectral $(8-14 \mu \mathrm{m})$ emissivities over the $400-800 \mathrm{~K}$ temperature range. Total hemispherical emissivities were estimated from the total normal values using $\varepsilon / \varepsilon_{\mathrm{n}}$ ratios from Fig. 7 .

Estimated uncertainties for the total hemispherical emissivity estimates were obtained from an rms sum of the original measurement uncertainty for the $8-14 \mu \mathrm{m}$ value, the uncertainty associated with the estimation of the total normal emissivity, and the uncertinty associated with the estimation of the total hemispherical emissivity. Therefore,

$$
\delta \varepsilon=\sqrt{(\delta \varepsilon)_{\text {meas }}^{2}+(\delta \varepsilon)_{\lambda \rightarrow t}^{2}+(\delta \varepsilon)_{n \rightarrow h}^{2}}
$$

The estimated uncertainty for the total normal emissivity was assumed to be $5 \%$ at $400 \mathrm{~K}$ and $15 \%$ at $800 \mathrm{~K}$. The estimated uncertainty for the total hemispherical emissivity was assumed to be $15 \%$ of the normal-to-hemispherical correction plus $5 \%$ of the normal emissivity.

Best estimates of total hemispherical emissivities at $400,550,700$, and $800 \mathrm{~K}$ are presented in Fig. 8, along with their estimated uncertainties. These values are also listed in Table 3. 


\begin{tabular}{|c|c|c|c|c|c|c|}
\hline \multicolumn{6}{|c|}{ Table 3. Estimates of total hemispherical emissivities and uncertainties for each sample. } \\
\hline & $\varepsilon$, safety rod & $\delta \varepsilon$, safety rod & $\varepsilon$, thimble & $\delta \varepsilon$, thimble & $\begin{array}{c}\varepsilon_{\text {, cooling }} \\
\text { tube }\end{array}$ & $\begin{array}{c}\delta \varepsilon, \text { cooling } \\
\text { tube }\end{array}$ \\
\hline $400 \mathrm{~K}$ & 0.177 & 0.022 & 0.124 & 0.020 & 0.091 & 0.0194 \\
\hline $550 \mathrm{~K}$ & 0.209 & 0.021 & 0.128 & 0.0135 & 0.095 & 0.0115 \\
\hline $700 \mathrm{~K}$ & 0.236 & 0.029 & 0.143 & 0.018 & & \\
\hline $800 \mathrm{~K}$ & 0.245 & 0.033 & 0,157 & 0.0225 & & \\
\hline
\end{tabular}

\section{SUMMARY}

Emissivity measurements have been obtained for selected materials used in a gamma-heating natural convection experiment. Three cylindrical samples were studied, including a $0.94 \mathrm{in.} O D$ stainless steel rod, an aluminum tube (thimble) and an aluminum cooling tube, using an infrared pyrometer sensitive to the $8-14 \mu \mathrm{m}$ wavelength range. Risults have been compared to literature values and a methodology for estimation of total hemispherical emissivity for these samples has been applied. 


\section{References}

1. Touloukian, Y. S., and DeWitt, D. P., eds., Thermophysical Properties of Matter, IFI/Plenum, TRPC Data Services. Vol. 7, 1970.

2. Siegel, R., and Howell, J. R., Thermal Radiation Heat Transfer, McGraw-Hill, 1972.

3. Sparrow, E. M., and Cess, R. D., Radiation Heat Transfer, augmented edition, McGraw-Hill, 1978.

4. Incropera, F. P., and DeWitt, D. P., Fundamentals of Heat and Mass Transfer, third ed., Wiley, 1990.

5. Dewitt, D. P., and Nutter, G. D., eds., Theory and Practice of Radiation Thermometry, Wiley, 1988.

6. Moffat, R. J., "Contributions to the Theory of Single-Sample Uncertainty Analysis," Journal of Fluids Eng., Vol. 104, pp. 250-260, 1982.

7. Woifram, S., Mathematica, A System for Doing Mathematics by Computer, Addison-Wesley, 1988. 


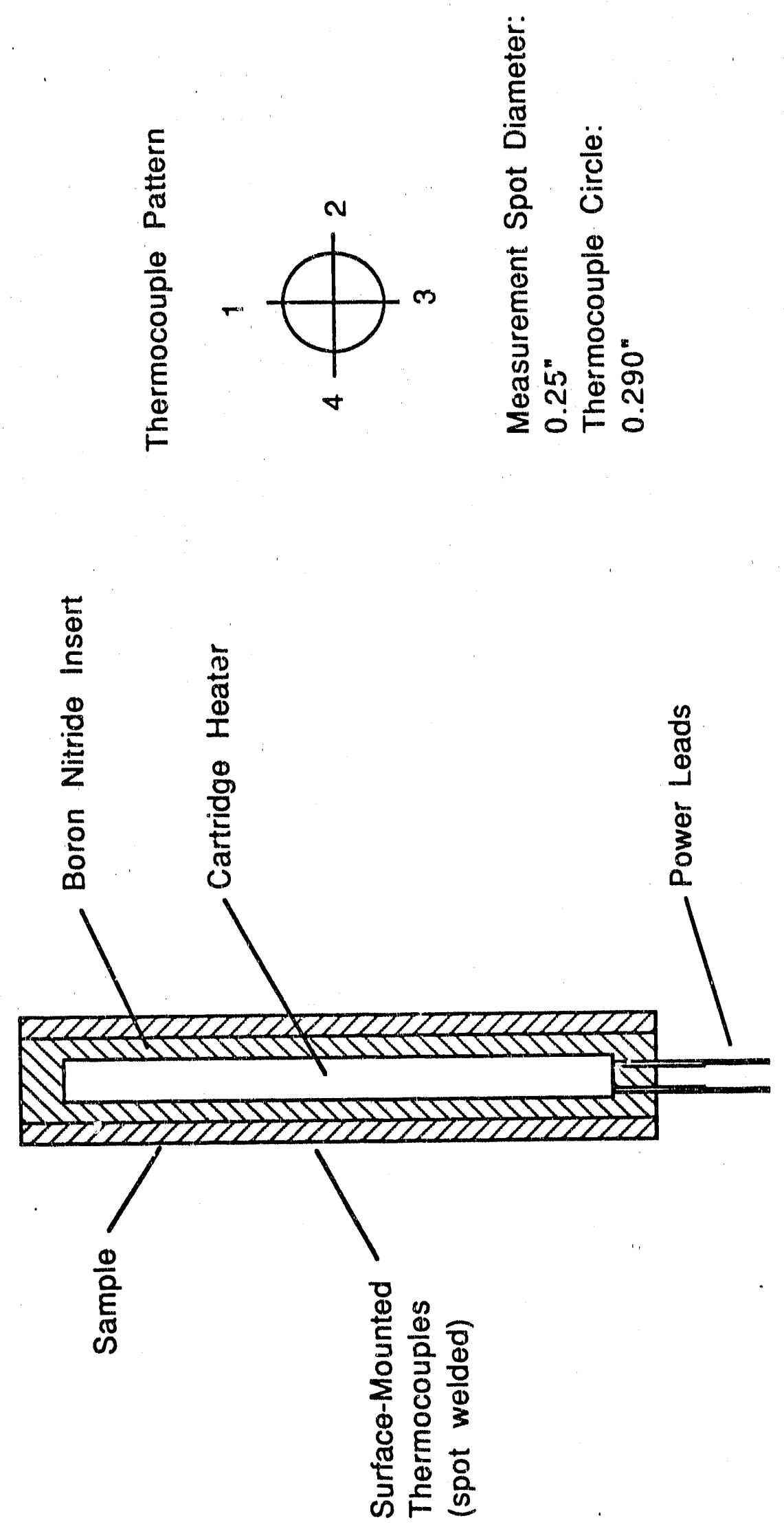

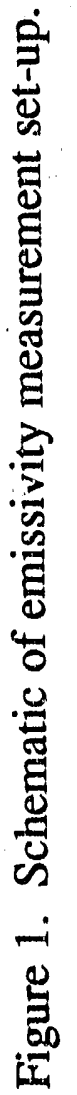




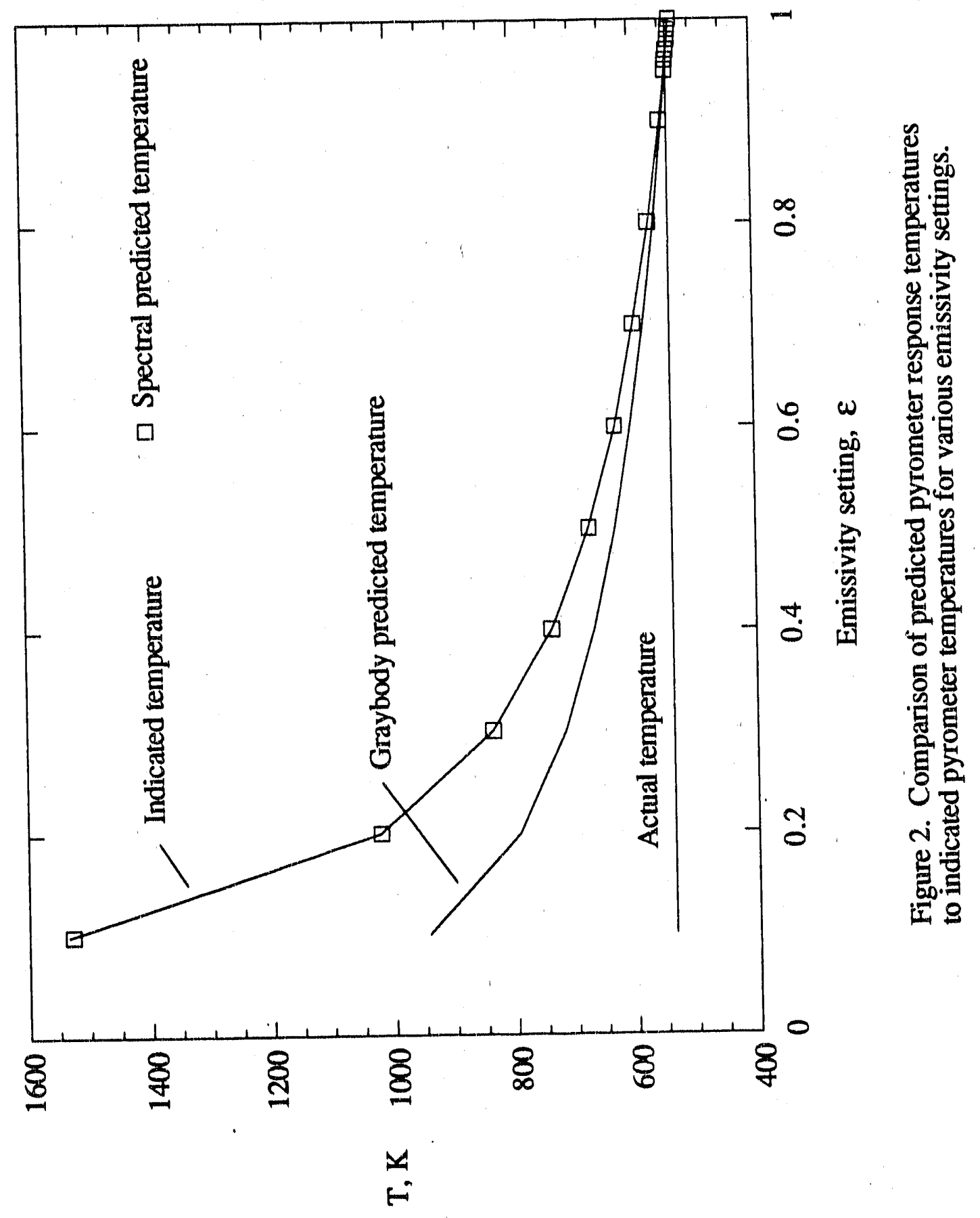




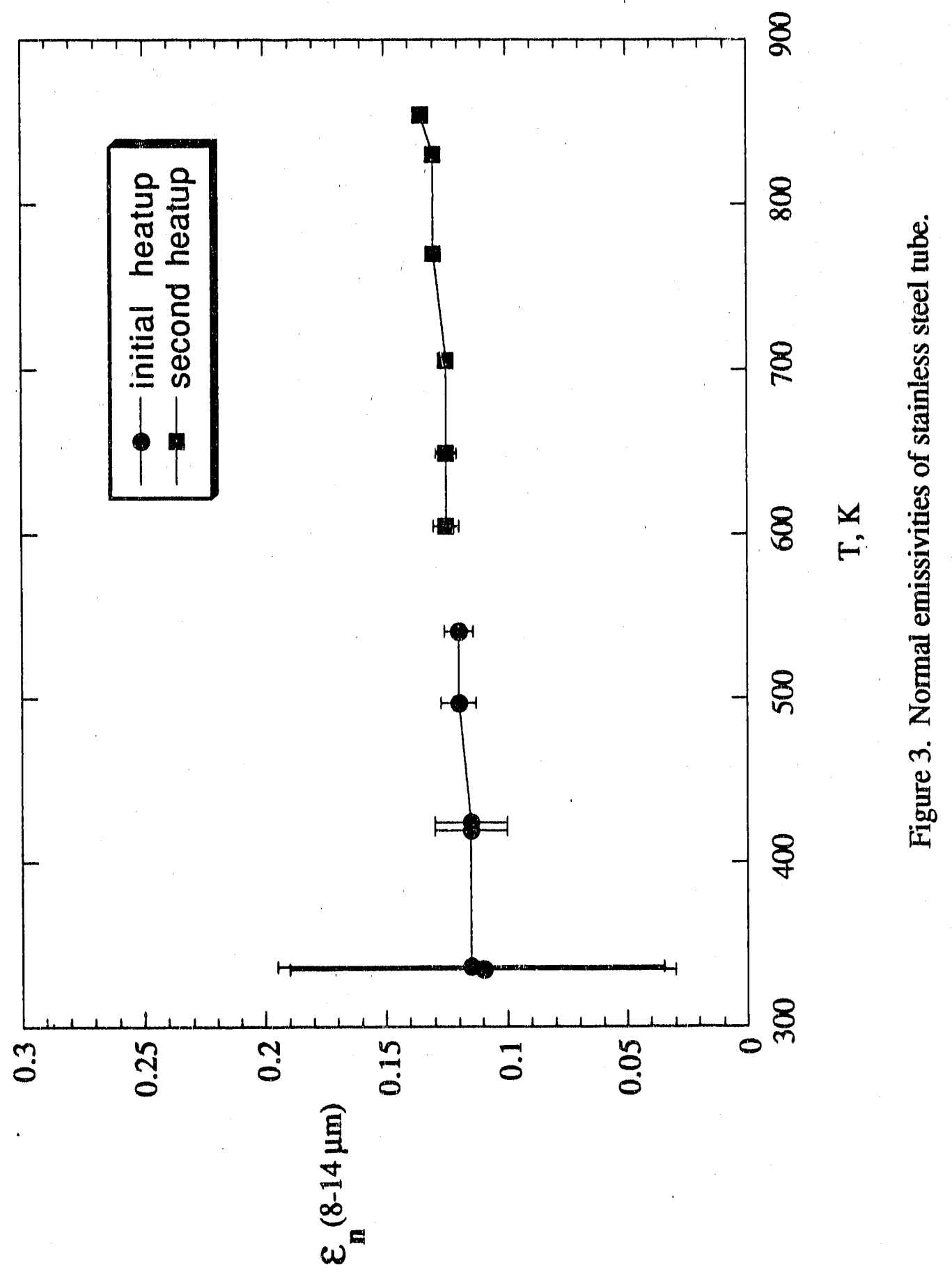




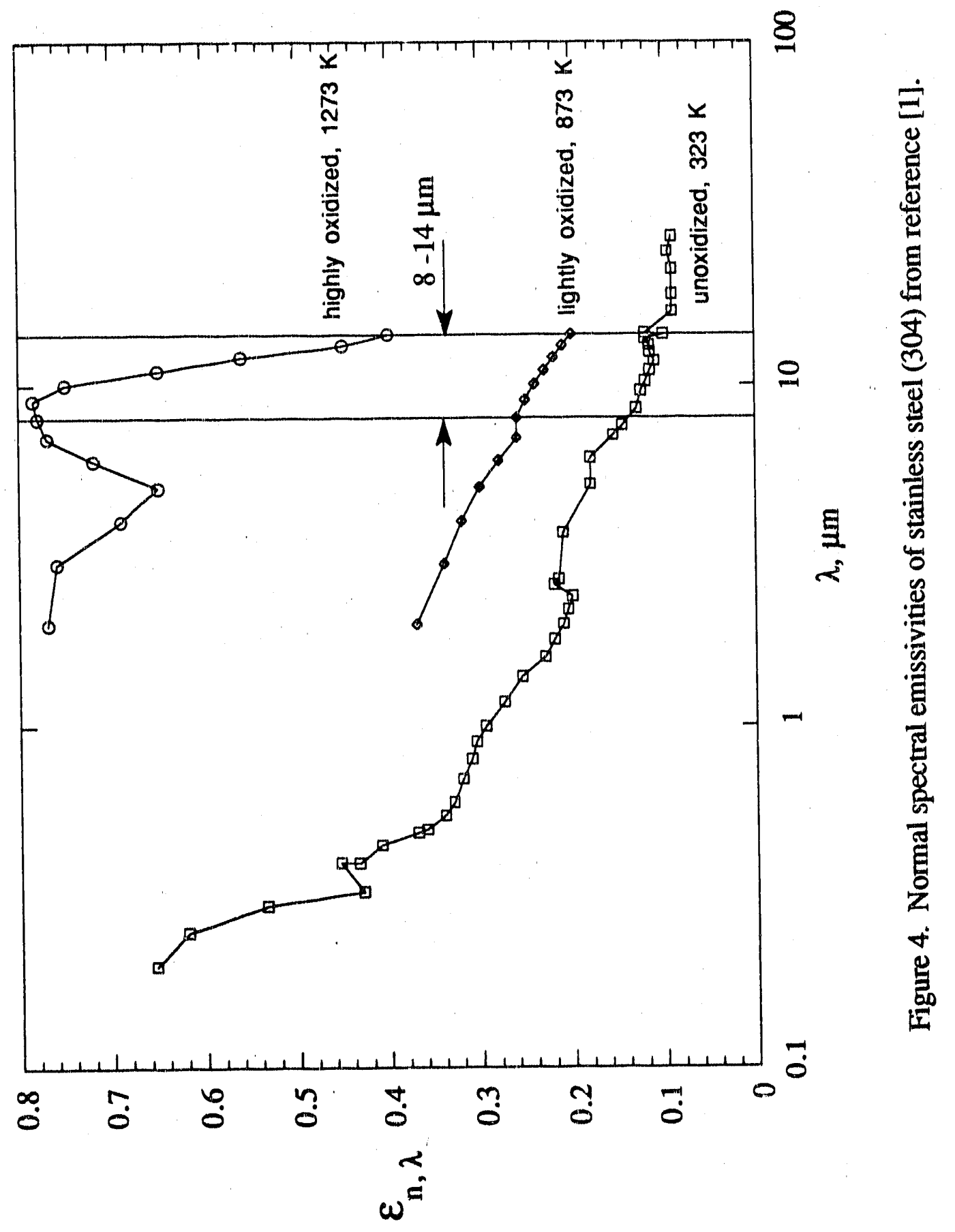




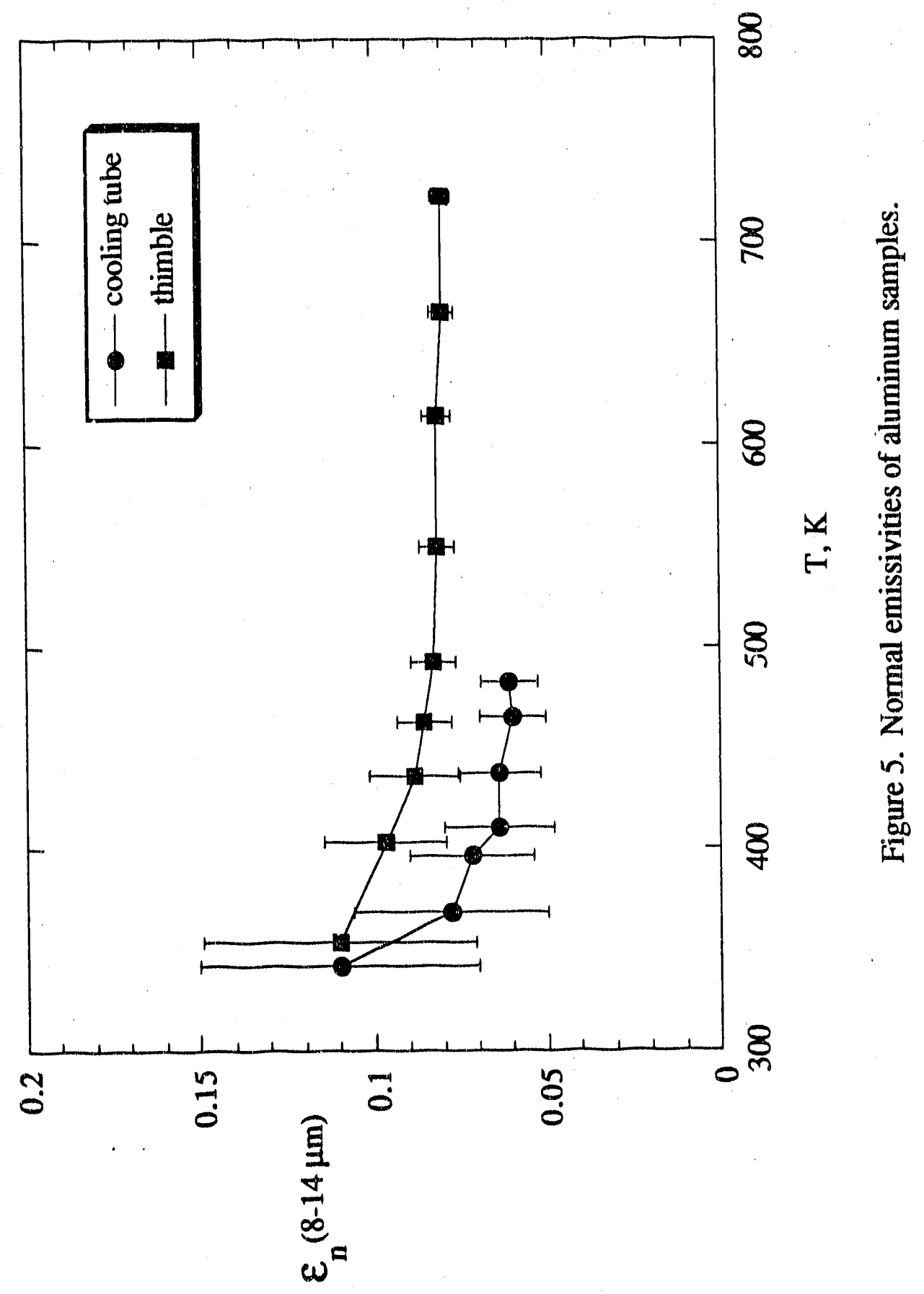




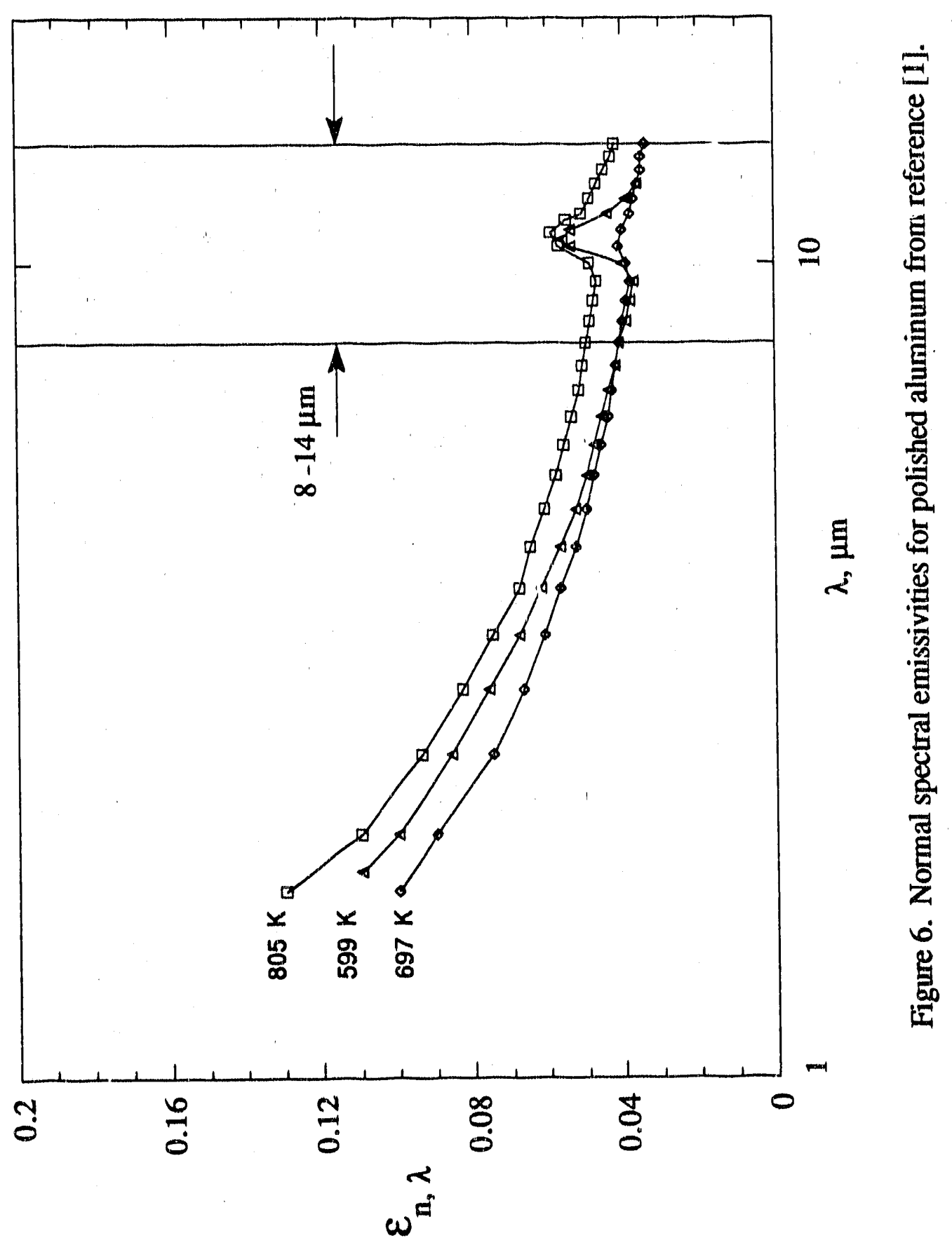




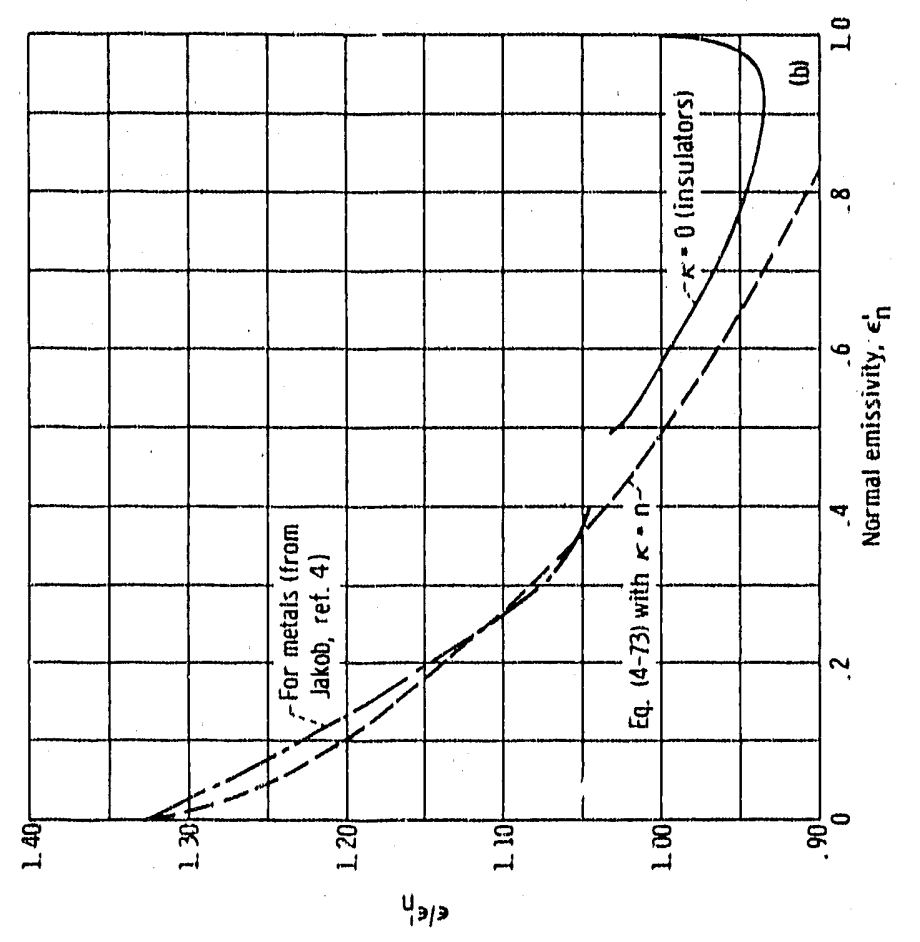

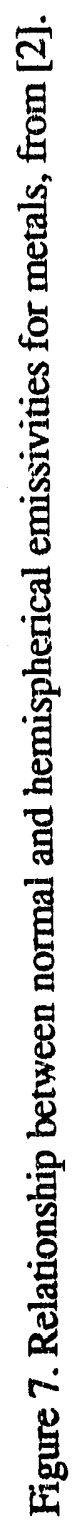




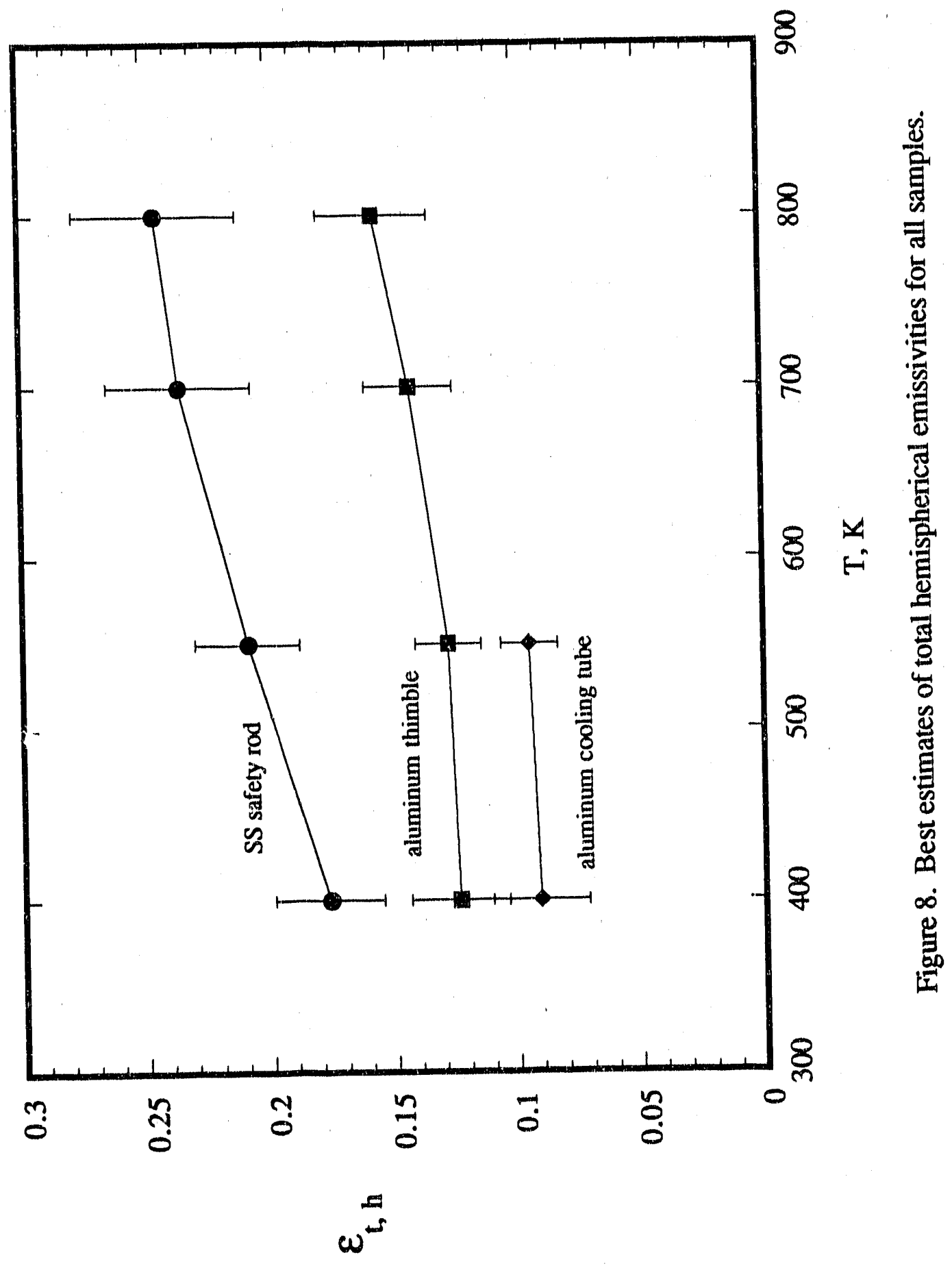


Appendix A

Infrared Pyrometer Characteristics and Specifications 


\section{Infra-red pyrometer characteristics}
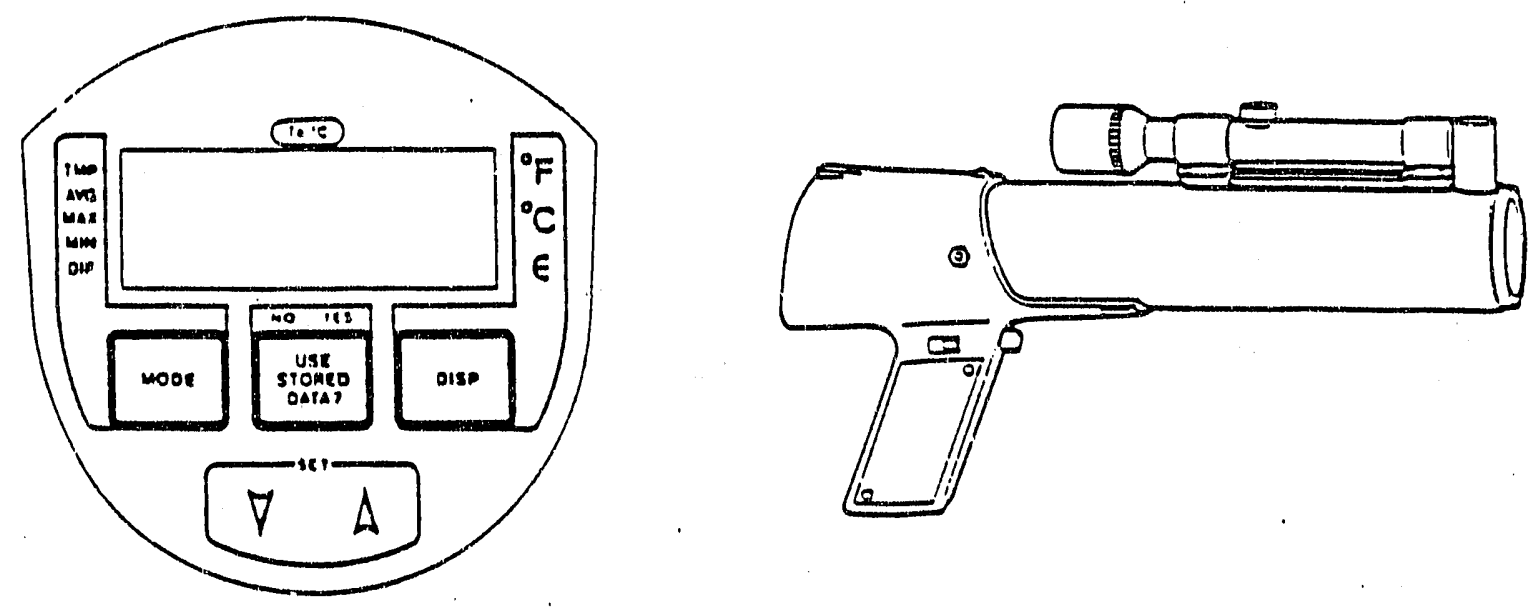

- Cassegrain optics focus infra-red radiation on thermopile detector

- Minimum spot size is 0.25 " at $24 "$

- Filters limit the wavelength sensitivity range to $8-14 \mu \mathrm{m}$

- Microprocessor provides corrections for $\varepsilon$ and $T_{a}$ variations based on user input 


\section{Models}

The Omegascope series is available in several models (identified by a serial number labe! on each instriment). The various models may be used for temperature measurement in general maintenance, product and process temperature monitoring, statistical quality control, and research. Each model (except OS-2101 and Agricultural units) includes a telescopic sight that increases aiming precision for small targets.

$\begin{array}{lc}\text { Low Temperature } & \text { OS-2101 } \\ \text { Low Temperature Scope } & \text { OS-2102 S } \\ \text { High Resolution } & \text { OS-2103 S } \\ & \\ & \\ \text { Close Focus 1 } & \text { OS-2104 S } \\ \text { Close Focus? } & \text { OS-2105 S }\end{array}$

Long Range

High Temperature

Glass

Agricultural

Sub-Zero
OS-2106 S

OS-3000 AS

Special Order

Special Order

Special Order
Basic model; uses oper-style sights.

Allows general-purpose measurement of smaller targets, at medium distances.

High-resolution model for general-purpose measurement of smaller targets at greater distances.

Special-purpose high-resolution models offering the capability to measure .25" $(6.4 \mathrm{~mm})$ and $.50 "(12.7 \mathrm{~mm})$ targets at $24^{\prime \prime}(0.6 \mathrm{~m})$ and $48 "(1.2 \mathrm{~m})$, respectively.

High-resolution model focused at infinity for long-range measurement applications, and general-purpose.

High-temperature model for measuring, metals, cement, glass, ceramics, heattreating, etc.

Designed specifically to measure glass surfaces.

Measures temperature with 0.1 degree resolution for agricultural and laboratory applications.

Measures temperatures from minus $110^{\circ} \mathrm{F}$ $\left(-80^{\circ} \mathrm{C}\right)$ to $250^{\circ} \mathrm{F}\left(120^{\circ} \mathrm{C}\right)$ for food processing, agricultural, and other applications.

All models (except glass, agricultural and sub-zero) include the Reflected Ambient Temperature Compensation feature. 
Omegascope Infrared Pyrometer Specifications

General Opèrating

Accuracy -

Repeatability

Emissivity

Reflected Ambient

Temperature Input Range

Display Resolution

Response Time

Power

General Environment

Operating

Storage

Temperature Range

Model

Low Temperature

Low Temperature Scope

High Resolution

Close Focus I, II

Long Range

High Temperature

Glass

Agricultural

Sub-Zero $\pm 1 \%$ of reading, \pm digit

$\pm 0.5 \%$ of reading, \pm 1 digit

0.10. to 1.00 in 0.01 steps, digital setting and display

LI: -17 to $1648^{\circ} \mathrm{C}$

HT: $400-3000^{\circ} \mathrm{C}$

1.0 degree ( 0.1 for Agricultural unit) in TMP, MAX, MIN, DIF display 0.1 degree in AVG display below $1000^{\circ} \mathrm{F}\left(500^{\circ} \mathrm{C}\right)$

250 milliseconds

$9 \mathrm{Vdc}$

32 to $120^{\circ} \mathrm{F} \quad 0$ to $50^{\circ} \mathrm{C}$ -40 to $150^{\circ} \mathrm{F} \quad-40$ to $60^{\circ} \mathrm{C}$

Degrees $\mathrm{F}$

-20 to 2500

-20 to 2500

-20 to 2500

-20 to 2500

-20 to 2500

750 to 5400

200 to 3000

-20 to 212

-110 to 250
Degrees $C$ -30 to 1400

-30 to 1400

-30 to 1400

-30 to 1400

-30 to 1400

400 to 3000

100 to 1600

-30 to 100

-80 to 120 
Optical

\begin{tabular}{|c|c|c|c|}
\hline $\begin{array}{c}\text { Distan } \\
\text { At }\end{array}$ & $\begin{array}{l}\text { e-to-Size-Ratio } \\
\text { ocal Point }\end{array}$ & $\begin{array}{l}\text { Minimum Spot } \\
\text { At Distance }\end{array}$ & $\begin{array}{c}\text { Spectral } \\
\text { Response }(\mu)\end{array}$ \\
\hline Low Temperature & $60: 1$ & $\begin{array}{l}0.5 "(1.3 \mathrm{Gm}) \\
\text { @ 30" (76 M) }\end{array}$ & $8-14$ \\
\hline Low Temperature Scope & $60: 1$ & $\begin{array}{l}1.0^{\prime \prime}(2.5 \mathrm{~cm}) \\
\text { (8) 60" (152 cm) }\end{array}$ & $8-14$ \\
\hline High Resolution & $90: 1$ & $\begin{array}{l}1.0 "(2.5 \mathrm{~cm}) \\
\text { (a) } 90(230 \mathrm{~cm})\end{array}$ & $8-14$ \\
\hline Close Focus I & $96: 1$ & $\begin{array}{l}.25 "(0.64 \mathrm{~cm}) \\
\text { (a 24" (61 cm) }\end{array}$ & $8-14$ \\
\hline Close Focus 2 & $96: 1$ & $\begin{array}{l}.50 "(1.3 \mathrm{~cm}) \\
\text { (a) 48" (122 cm) }\end{array}$ & $8-14$ \\
\hline Long Range & $96: 1$ & $\begin{array}{l}10.0^{\prime \prime}(25.4 \mathrm{~cm}) \\
\text { @ } 100 \mathrm{ft} .(30.5 \mathrm{M})\end{array}$ & 8-14 \\
\hline High Temperature & $167: 1$ & $\begin{array}{l}1.1^{\prime \prime}(2.8 \mathrm{~cm}) \\
\text { @ 180" }(457 \mathrm{~cm})\end{array}$ & $2.1-2.3$ \\
\hline Class & $60: 1$ & $\begin{array}{l}1.0^{\prime \prime}(2.5 \mathrm{~cm}) \\
@ 60^{\prime \prime}(152 \mathrm{~cm})\end{array}$ & $4.9-5 .: i$ \\
\hline Agricultural & $15: 1$ & $\begin{array}{l}2.6 "(6.6 \mathrm{~cm}) \\
\text { (9) 40" (102 cm) }\end{array}$ & 8-14 \\
\hline Sub-Zero & $30: 1$ & $\begin{array}{l}1.3 "(3.3 \mathrm{~cm}) \\
\text { (8) 40" (102 cri) }\end{array}$ & 8-14 \\
\hline
\end{tabular}




\section{Appendix B}

Mathematica Algorithms for Calculating Emissivities and Uncertainties 
uncert 2

Algorithm for calculating amissivity uncertainties:

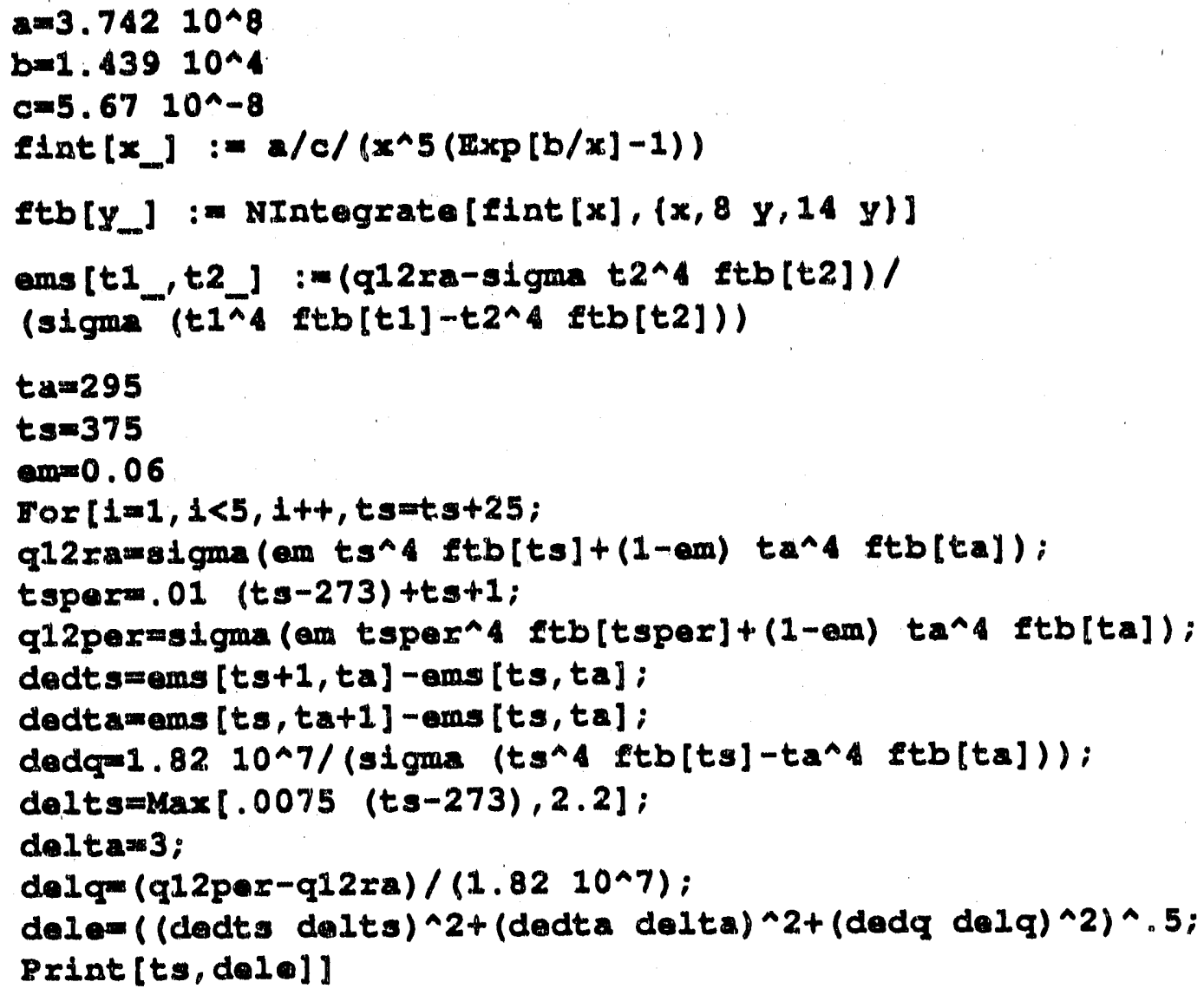

Algorithm fox calculating an unknown emissivity based on readings obtained at some temperature other than the actual surface temperature:

(top values for em,ts, and ta are the "gun" valuos. Bottom values are tho "actual" values.)

$\operatorname{com} .11$

$\tan (52+459.67) / 1.8$

$t=30+273$

q12ranaigma (am ts^4 ftb[ts]+(1-om) ta^4 ftb[ta])

$\operatorname{tg}=(152+459.67) / 1.8$

$t a=22+273$

ems [ts, ta] 
uncert 2

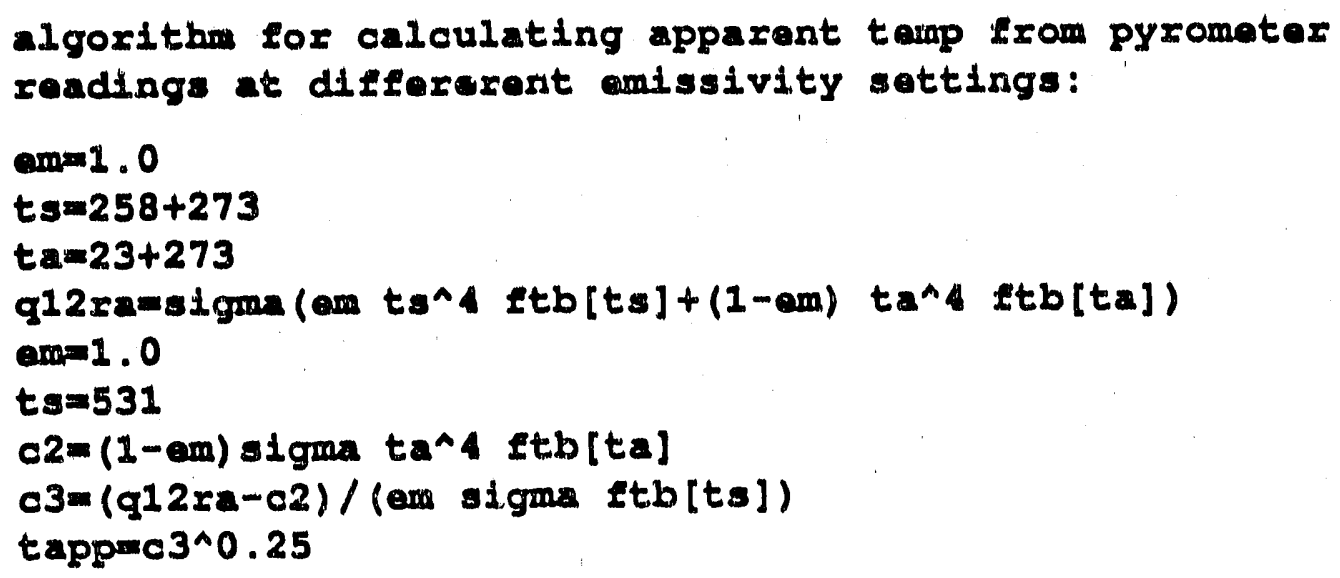




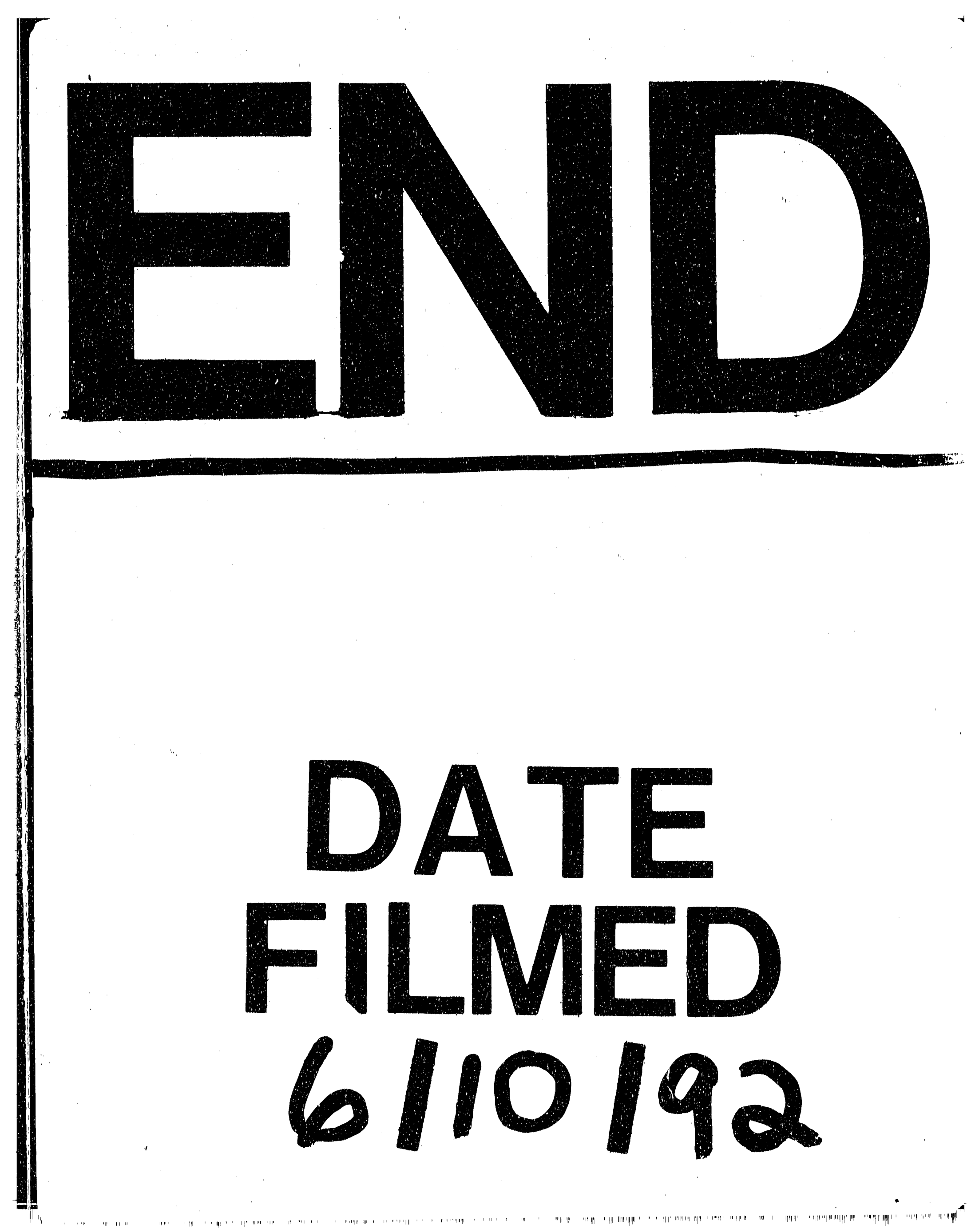


